\title{
Tribological interactions of advanced polymeric coatings with polyalkylene glycol lubricant
} and r1234yf refrigerant

\author{
M. Wasim Akram ${ }^{1,2}$, Jacob L. Meyer ${ }^{3}$, Andreas A. Polycarpou ${ }^{1,2^{*}}$ \\ ${ }^{1}$ Mechanical Science and Engineering Department, University of Illinois at Urbana-Champaign, \\ Urbana, Illinois, USA \\ ${ }^{2}$ Mechanical Engineering Department, Texas A\&M University, College Station, Texas, USA \\ ${ }^{2}$ ATSP Innovations, Champaign, Illinois, USA \\ *Corresponding: Tel. (979) 458-4061; apolycarpou@tamu.edu
}

\begin{abstract}
We report on the tribological performance of an aromatic thermosetting polyester (ATSP) blended with polytetrafluroethylene (PTFE as a coating material for air-conditioning compressor applications. Tribological experiments were conducted in the presence of environmentally friendly r1234yf refrigerant and polyalkyleneglycol (PAG) lubricant, to compare state-or-the-art polymeric coatings with ATSP/PTFE. Results showed better performance for ATSP/PTFE, compared to PTFE-based and Fluorocarbon- based coatings under both dry and boundary lubricated sliding conditions. Significant reduction of $69 \%$ in friction was obtained with the inclusion of PAG lubricant, suggesting a synergistic combination for ATSP/PTFE and PAG/r1234yf. Morphological evolution via scanning electron microscopy revealed surface cracks and voids for PTFE/MoS 2 , responsible for negative interactions under lubricated condition, which was not the case for ATSP/PTFE coating.
\end{abstract}

Keywords: Compressor; polymeric coating; refrigerant; ATSP/PTFE 


\section{Introduction}

In recent years, increasing demand for reliable and efficient operation of air-conditioning and refrigeration compressors has driven intensive research and industrial efforts towards the development of polymeric coatings-based surface modifications [1-3]. The critical tribomechanical systems are often subjected to aggressive tribological conditions associated with higher sliding velocities and loads along with inadequate replenishment of the liquid lubricant at the contact interface. These system parameters, therefore, limit the effectiveness and functionality of liquid lubricants, necessitating the development of protective solid polymeric coatings. However, shifting from liquid to solid lubricant requires system modifications, which might be expensive. Furthermore, during this transitional phase the existence of polymeric coatings and liquid lubricants will overlap, resulting in an interaction of polymer materials and liquid lubricant under contact conditions. Such kind of interaction is critically important and plays a vital role to determine the tribological performance of coatings/lubricants systems. Nevertheless, scientific attempts to elucidate the interactions between polymers and liquid lubricants are scarce, especially addressing the issues related with tribo-compatibility of automotive air-conditioning systems. Note that, an adverse reaction may lead to an early failure of the mechanical components due to severe wear or higher friction. Such negative effects could be alleviated by using advanced polymeric coatings that offer improved tribological performance, and positive interaction with the existing system environment (working medium and lubricant). Therefore, a detailed tribological investigation is required to identify the functional polymers, demonstrating frictional and wear behavior under air-conditioning compressor -specific operating conditions. Herein, we consider air-conditioning compressor systems as the potential application field for polymeric coatings to investigate the tribological performance of advanced coatings and their interaction with current state-of-the-art synthetic lubricants in the presence of environmentally friendly r1234yf refrigerant. 
Commercially available PTFE- and Polyether ether ketone (PEEK) -based high bearing polymeric coatings have attracted the attention of several researchers in the field of airconditioning compressor systems in recent years [4-7]. Among the candidate coating materials, PTFE has received significant attention due to its low shear strength, and resulting low friction coefficient $[8,9]$. However, continuous transfer of the polymeric materials to the counter surface is a typical characteristic of PTFE material, causing a higher wear rate. Thus, different filler materials are blended with PTFE to improve its wear resistance and thus control the wear rate of PTFE. For example, PEEK blended with 10-20\% PTFE showed better tribological behavior, ensuring low friction coefficient and high wear resistance compared to neat PTFE [10, 11]. Nunez et al. applied this coating for a Mobile Air Conditioning (MAC) system in the presence of 1, 1, 1, 2-Tetrafluoroethane (r134a) refrigerant [4]. They reported better tribological performance for this coating compared to PTFE/MoS 2 coating. However, their work cannot be transferred to modern MAC systems due to change of the working environment (refrigerant in this case). Note that, the tribological performance of polymeric materials and coatings significantly depends on the working environment i.e., refrigerant and lubricant. Yeo et al. studied the tribological performance of PEEK and PTFE based coatings for MAC systems in the presence of alternative refrigerant carbon dioxide ( $\mathrm{r} 744) \mathrm{CO}_{2}$ [6]. Interestingly, they demonstrated better performance for PTFE/MoS 2 compared to PTFE/PEEK coating in $\mathrm{CO}_{2}$ environment, unlike HFC-134a based refrigerant. This would further support the dependency of the working environment on the tribological performance of the polymeric coatings. Note that, automotive compressor industries are now implementing low global warming potential (GWP) refrigerants due to environmental regulations as directed by the Environmental Protection Agency (EPA), Kyoto, and Montreal Protocols. As a result, several alternative refrigerants have been developed. Among the potential candidates, r1234yf is considered as a next generation refrigerant in MAC systems for possessing 
lower GWP and compatible thermo-physical properties compared to r134a [12-14]. Thus, understanding the tribological interactions of advanced polymeric coatings and r1234yf is essential to design advanced and sustainable compressor systems.

To-date no relevant research, addressing the tribological performance of polymeric coatings in r1234yf environment, is available. Akram et al. investigated the responses of metallic interface and lubricants for this newly developed environmentally friendly refrigerant [15-17]. They demonstrated the existence of a frictional instability for this refrigerant, indicating required optimization of the lubricant or the use of protective coatings, such as polymeric-based coatings. This warrants a comprehensive study to measure the tribological performance of polymeric coatings in the presence of r1234yf refrigerant under both dry and boundary lubricated conditions. The aforementioned coatings for MAC system produced some degree of wear, limiting the effectiveness of the coating system. Moreover, wear particles can easily get trapped into the refrigeration cycle systems and will deteriorate the overall performance of the refrigerant cycle. Thus it is necessary to formulate new coatings with almost no wear. Along this line, a new coating, ATSP blended with PTFE has been developed and optimized for compressor applications [18-20]. This material has good thermal and dimensional stability along with very high wear resistance.

In this study, we evaluated the tribological performance of four different polymeric coatings including the newly synthesized ATSP/PTFE material using controlled tribological experiments. We considered two different experimental conditions, namely dry and boundary lubricated, to investigate the mutual influence of the coatings and the lubricants on the tribological performance. Post-experimental characterization of the worn surfaces was carried out to quantify the wear via profilometric scans. Furthermore, morphological analysis was conducted to reveal 
the underlying wear mechanisms using Scanning Electron Microscopy (SEM) and Energy Dispersive Spectroscopy (EDS).

\section{Aromatic thermosetting polyester (ATSP)}

The ATSP material was invented in the mid-1990s [21, 22]. Since then, further development of this material, as far as its powder synthesis, bulk fabrication, coating application, and tribological performance, has been undertaken. This material possesses the backbone structure of polyester, which has the tendency to exhibit liquid crystallinity [23]. Note that, polymer tribological performance can be improved with the introduction of liquid crystallinity, as addressed by numerous studies $[24,25]$. Thus, the beneficial effect of liquid crystallinity in ATSP has made this material a potential candidate for tribological applications. Furthermore, ATSP exhibits good dimensional and thermal stability (up to $350^{\circ} \mathrm{C}$ in air and $425^{\circ} \mathrm{C}$ in nitrogen), good resistance to flame and ablation, good chemical resistance, and good adhesion and repair capabilities. Additionally, ATSP shows the characteristic of Interchain Transesterification Reactions (ITR), which facilitates the synthesis process and recovers micro-crack and voids in the material system. The synthesis of the ATSP blend with PTFE materials is discussed below.

\subsection{Synthesis process}

Two end groups, namely carboxylic acid (oligomer C2) and acetoxy (oligomer A1), are used as the precursors of ATSP materials as shown in Fig. 1. These oligomers were made from a mixture of hydroquinone diacetate (HQDA), p-acetoxybenzoic acid (ABA), isophthalic acid (IPA), and trimesic acid (TMA). Oligomer C2 and A1 was produced by mixing TMA, ABA, IPA and HQDA as a molar ratio of $1: 6: 4: 4$ and 2:5:2:7, respectively. The oligomers were mixed in a ratio 1.44:1.00 by weight (C2/A1) and then dissolved in N-Methyl-2-Pyrrolidone solution. The oligomers were then processed through several synthesizing and curing steps until obtaining the final solidified products. The solidified products were then grounded to fine powder in order to 
facilitate the mixing with PTFE. The powders were dissolved into N-Methyl-2-Pyrrolidone solution and sprayed over gray cast iron samples to apply it as a coating. Coating uniformity was maintained through controlled spray rate per pass. Further details of the synthesis process can be found elsewhere [26].

\subsection{Tribological application}

Earlier studies on the tribological performance of ATSP material has been for bulk composites. For example, Demas et al. investigated a wide range of compositions using blends of ATSP with polytetrafluoroethylene (PTFE) [19]. PTFE has been widely used because of its unique characteristics of chemical inertness, high and low-temperature stability, and excellent lubricity. However, PTFE shows poor wear resistance due to continuous transfer of material to the counter surface. Such issues can be mitigated with the inclusion of fillers, including PEEK $[10,11], \mathrm{MoS}_{2}$ [27, 28], Graphite, and Polyimide. Nevertheless, no matter which filler is used, any improvements towards the wear resistant generally occur at the expense of lubricity. On the other hand, neat ATSP material shows comparatively higher friction [19]. Therefore, this is believed that blend of ATSP and PTFE will offer better interfacial integrity, meaning low wear and low friction.

ATSP is considered as a potential candidate for advanced tribological interfaces for possessing good thermal and dimensional stability along with strong adhesive nature to the surface. Huang et al. demonstrated improved surface integrity and tribological performance for ATSP blended with ultrahigh molecular weight polyethylene (UHMWPE) and polyethylene-co-acrylic (PEA) acid as compatibilizer [18]. They reported almost zero wear and self-healing nature of ATSP/UHMWPE (with PEA) to counter surface voids and micro-cracks. Such study is applicable for biotribological applications, for example, in the field of hip-joint assemblies. Demas et al. studied the tribological performance of different blends of ATSP and PTFE for air-conditioning 
compressor applications [19]. In their study, they compared ATSP/PTFE bulk materials with high bearing state-of-the-art commercially available polymers to investigate their friction and wear behavior. They also reported excellent wear resistance for ATSP when an optimum PTFE-based blending composition was used. In a different study, Zhang et al. also showed superior performance of ATSP with fluoro-additives, applied as powder solid lubricant, compared with high-grade PTFE coatings [20]. Nonetheless, these studies were conducted for bulk composite and under dry conditions only. Note that, the tribological behavior of a material as a coating will likely be different from the bulk system due to imposed boundary conditions. The boundary of a coating is confined by air-coating interface and coating-substrate interface. Besides the geometrical constrain issues, the tribological performance of polymeric systems strongly depends on working environments, for example the presence of lubricant and refrigerant. In this study, tribological investigation for state-of-the-art coatings and advanced ATSP/PTFE coatings under dry and boundary lubricated conditions and in the presence of r1234yf refrigerant is carried out.

\section{Experimental details}

\subsection{Tribological conditions}

A swash-plate type automotive air-conditioning compressor geometry was experimentally simulated using a specialized high pressure tribometer (HPT). The pins used in this work were from actual components of automotive air-conditioning compressors, referred to as "shoes." The shoe surface is crowned to retain the lubricant during boundary lubricated sliding contact, as shown in Fig. 2. A self-aligned holder is used for the shoe to ensure evenly distributed normal contact load.

First, two sets of experiments were performed with all the coating materials: under dry/unlubricated conditions (set 1) and under boundary lubricated conditions (set 2). All the experiments were carried out under a normal load of $445 \mathrm{~N}$ and sliding velocity of $3.6 \mathrm{~m} / \mathrm{s}$ (1500 
rpm). Note that, such experimental conditions have been used in previous studies for $\mathrm{CO}_{2}[6]$ and HFC-134a refrigerants [4]. Second, a separate set of experiments was performed with ATSP/PTFE and PTFE/MoS 2 coatings. These two coatings have been chosen due to the fact that they represent two extreme performance characteristics (best and worst). For this set of experiments, tribological tests have been carried out for $60 \mathrm{~min}$ at a sliding velocity of $3.6 \mathrm{~m} / \mathrm{s}$ to produce $12000 \mathrm{~m}$ of sliding distance. A small amount of lubricant (46 mg) is directly applied at the interface to develop boundary lubrication conditions. A commonly used Polyalkylene Glycol (PAG) based lubricant is used for this study. This lubricant is synthetic and suitable for r1234yf refrigerant [17].

The tribology chamber pressure was kept constant at $0.3 \mathrm{MPa}$ using $\mathrm{r} 1234 \mathrm{yf}$ refrigerant. The operating temperature was set to $90^{\circ} \mathrm{C}$, which is typically found at the outlet of automotive airconditioning compressor systems. Each experiment was performed at least twice (typically three times) to ensure reputability. The experimental conditions are summarized in Table 1.

\subsection{Tribological samples}

Five different coatings, namely PTFE/PEEK, PTFE/Pyrrolidone, PTFE/MoS 2 , Fluorocarbon and ATSP/PTFE, were used in this study. These coatings were deposited on gray cast iron substrates. Note that, gray cast iron is one of the most commonly used materials for air conditioning compressor systems. The coatings were obtained from different suppliers. Therefore, the actual compositions of the coatings were somewhat unknown as they are propriety. However, some information regarding these coatings can be found elsewhere [6]. Noteworthy, ATSP/PTFE is consisted of ATSP and 5\% weight of PTFE only. No other substances or fillers have been used in this polymeric composite, unlike traditional commercial coatings. The glass transition temperature for ATSP is about $240{ }^{\circ} \mathrm{C}-285{ }^{\circ} \mathrm{C}$ and its hardness is about 83 (Shore E) on Rockwell standard. Other thermo-physical and mechanical properties can be found in supplier's 
catalogs. For direct comparison, all the coatings have a similar thickness $(20-30 \mu \mathrm{m})$ and surface roughness. All the samples were cleaned ultrasonically under submerged solution of isopropyl alcohol followed by drying using warm air. The coating materials and thickness values are listed in Table 2.

\section{Tribological results}

\subsection{Friction}

Fig. 3 depicts the frictional behavior of the five polymeric coatings, measured from controlled tribological experiments. Fig. 3(a) represents the variation of the coefficient of friction (COF) versus sliding distance, under dry conditions. Among the tested samples, ATSP/PTFE exhibited superior performance, resulting in stable and steady COF. The COF was about 0.077, which was the lowest compared to the other coatings. PTFE/Pyrrolidone and PTFE/MoS 2 showed almost similar frictional behavior in the presence of r1234yf refrigerant. The friction coefficient was about $0.075-0.085$ in these cases, which was comparable to the ATSP/PTFE based coatings. On the contrary, an intermediate transitional behavior was observed for PTFE/PEEK based coating, suggesting a reactive interface like the metallic contacts associated with r1234yf refrigerant. Note that, such kind of 'run-in' behavior is a typical tribological characteristic of r1234yf/PAG refrigerant [13]. This transitional run-in will cause an unstable interface, causing fluctuation in frictional energy, which is not desired for sustainable operation. In the case of Fluorocarbonbased coatings, the tribological performance was poor under this refrigerant condition, causing a COF fluctuation between 0.12 and 0.21 . However, no sharp rise in friction coefficient was observed in this case, suggesting no metallic contacts.

Friction characteristics of the polymeric coatings under boundary lubrication are shown in Fig. 3(b). Similar to dry conditions, ATSP/PTFE showed excellent performance under boundary lubrication. The COF was very low at about 0.05 , which is about $33 \%$ less than the dry condition. 
No fluctuation in the COF was observed, meaning a steady and stable interface. Interestingly, for the case of PTFE/MoS 2 the friction coefficient was higher (about 0.16 ) compared to the dry condition $(\mathrm{COF} \sim 0.080)$. This could be due to the impediment of the transfer film, resulting from adverse interaction between PTFE/MoS 2 and PAG lubricant. This phenomenon will be discussed later with the aid of SEM analysis. On the other hand, Fluorocarbon-based coatings failed before completing the experiments under boundary lubrication conditions. The COF increased abruptly at the onset of the catastrophic failure, meaning possible metallic contacts by removal of the coating completely. This inferred a negative interaction between fluorocarbon particles and PAG lubricant in r1234yf environment.

\subsection{Microscopy}

Fig. 4 shows optical microscopy images of the worn disks tested under dry conditions. No significant wear marks or surface damage was observed for PTFE/ATSP disk sample, Fig 4(a). Refer to Fig. 4(b), some polishing of the disk sample was seen under optical microscope, indicating materials removal form the coating surface. In the case of Fluorocarbon based coatings, the substrate material of the cast iron was revealed as can be seen in Fig. 4(c). Thus, for this system, fluorocarbon-based coating was removed almost completely from the surface. However, the substrate material was not clearly seen, meaning the remnant of a thin fluorocarbon-based layer near the coating-substrate interface. Fig. 4(d) shows worn disk sample for PTFE/PEEK coating where no severe surface damage was observed. The wear track was clearly seen for PTFE/MoS 2 as can be seen in Fig 4(e). However, no deep scratches were observed for non-lubricated conditions in r1234yf environment.

Fig. 5 shows optical microscopy images for the tested (worn) disk samples under boundary lubricated conditions. PTFE/ATSP showed no wear scar on the surface, meaning better topographical integrity. This shows that the ATSP/PTFE coating system did not undergo severe 
contact conditions under lubricated environment, suggesting a synergistic effect between the coating, metal pin, refrigerant and lubricant. The underlying mechanism will be elucidated later with the aid of morphological analysis. In the case of PTFE/Pyrrolidone, no significant surface damage was seen for lubricated conditions. On the contrary, for the PTFE/PEEK coating system, some deep wear scratches ware observed. Interestingly, a rough topography associated with deep wear scratches was seen for PTFE/MoS 2 coating. Therefore, it is conjectured that PTFE/MoS 2 experienced a continuous loss of material from the top surface under boundary lubrication, meaning adverse interactions between PTFE/MoS 2 and PAG lubricant, as mentioned in the previous section. Note that the Fluorocarbon coating material showed complete removal of the coating, exposing the substrate of cast iron material. In addition, the substrate material also experienced scuffing type failure, which is in accord with frictional behavior (sharp rise in friction behavior). This implied that fluorocarbon particles acted adversely with PAG lubricant system, resulting in severe scuffing type failure, in accord with the friction behavior.

\subsection{Wear}

Fig. 6 shows quantitative wear profiles of worn polymeric disk samples tested under both dry and lubricated conditions. Almost zero wear was measured for ATSP/PTFE coating under both dry and lubricated conditions, as can be seen in Fig. 6(a). On the other hand, PTFE/MoS 2 (Fig. 6(e)) showed low wear under dry conditions only. The measured wear depth in this case was about 2.5 $\mu \mathrm{m}$. However, this was increased to about 6-7 $\mu \mathrm{m}$ for the lubricated condition along with $15 \mu \mathrm{m}$ deep wear scratches. This inferred that PTFE/MoS 2 interacts negatively with PAG/r1234yf system, producing significant surface cracks and micro voids.

The fluorocarbon based coating exhibited complete removal of the coatings from the surface regardless of sliding conditions, as can be seen in Fig. 5 (c). In both cases (unlubricated and boundary lubricated), the average wear depth is about $30 \mu \mathrm{m}$, which is equal to the coating 
thickness. Note that, the lubricated conditions were more severe, compared to the dry condition as identified by abrupt increases in the COF measurements, and substrate scuffed areas. Under dry conditions, the wear debris acted as a third body lubricant to protect the substrate from further wear. However, under lubricated conditions, the interface scuffed and caused scuffing failure to the substrate as well (wear scratch exceeded $40 \mu \mathrm{m}$ ), well into the cast iron substrate disk. PTFE/Pyrrolidone (Fig. 6(b)) showed better performance for lubricated condition similar to the ATSP/PTFE coating. However, the wear depth was higher for the dry condition, compared to ATSP/PTFE coating.

\subsection{Durability experiments}

Based on the results from the comparative study of the five polymeric coatings (discussed in the previous section), two of the coatings were selected for further investigation to understand the underpinning synergistic and/or antagonistic performance between polymer coating, lubricant and refrigerant. Fig. 7 depicts the tribological results, obtained from long duration experiments of 12,000 m sliding distance. Fig. 7(a) and 7(b) show the COF behavior under unlubricated and boundary lubricated conditions, respectively. Under dry conditions, the COFs were similar for both PTFE/ATSP and PTFE/MoS 2 coating systems (0.067 versus 0.074$)$, as can be seen in Fig. 7(a). However, under boundary lubricated conditions, a distinct behavior is observed. The COF for PTFE/ATSP still remained stable and lower compared to dry condition. Interestingly, the COF for PTFE/MoS $\mathrm{M}_{2}$ became unstable with the inclusion of PAG lubricant at the interface. The near contact temperature (NCT) was higher (about $180{ }^{\circ} \mathrm{C}$ ) for ATSP/PTFE compared to

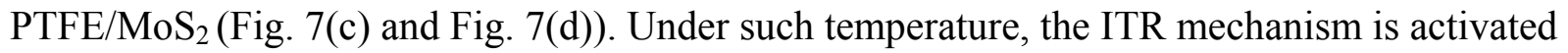
for ATSP material and provides better surface integrity by self-healing of voids and micro-cracks $[18,26]$. 
Typical profilometric wear scans of the two coatings, namely PTFE/ATSP and PTFE/MoS 2 ,

tested under both unlubricated and boundary lubricated conditions are shown in Fig. 8. Under dry conditions, higher wear depth was measured for PTFE/MoS 2 compared to PTFE/ATSP (average

wear depth $4 \mu \mathrm{m}$ versus $1.5 \mu \mathrm{m}$, respectively). Note that, in the case of shorter duration experiments (30 min or about $6,000 \mathrm{~m}$ sliding distance), the measured wear depths were $1.0 \mu \mathrm{m}$ and $2.5 \mu \mathrm{m}$ for PTFE/ATSP and PTFE/MoS 2 , respectively. This implies that PTFE/ATSP offers better wear resistance compared to PTFE/MoS 2 . Interestingly, the wear increased significantly in the case of PTFE/MoS 2 for boundary lubricated conditions. This observation is in accord with the previous short duration experiments. About $8 \mu \mathrm{m}$ of average wear depth was measured in this case. This was significantly high compared to PTFE/ATSP (average wear depth was about $1 \mu \mathrm{m}$ ). These observations inferred a synergistic effect for PTFE/ATSP and PAG lubricant, while antagonistic effect for PTFE/MoS 2 and PAG lubricant.

\section{SEM morphological analysis}

\subsection{Morphology of coatings}

SEM analysis was performed via a JEOL 6060LV instrument. An exciting voltage of $10 \mathrm{kV}$ was used to obtain these micrographs. All the samples were sputtered with Au-Pd for 35 seconds at a rate of $4 \mathrm{~nm} / \mathrm{sec}$ prior to measuring the SEM images to reduce conductivity issues. Fig. 9 depicts SEM images of the untested and tested samples of ATSP/PTFE coating. Surface segregation was revealed from this analysis, ensuing a textured pattern as can be seen in Fig. 9(a). This surface segregation and texture are likely developed through the ATSP crosslinking process [29, 30]. In addition, polymeric crystallinity caused surface segregation due to micro-phase separation at the air-polymer interface [31-33], which will be discussed below.

Note that, Kun et al. also observed surface segregation on ATSP blended polyimide surface [34]. They utilized different analytical instruments in order to find the mechanisms underlying this 
phenomenon. They reasoned that surface segregation was originated due to crosslinking of ATSP in conjunction with differences in molecular weights between ATSP and polyimide. This surface segregation can govern the tribological performance. Fig. 9(b) represents the worn disk sample after a tribological experiment under boundary lubrication. Material enrichment associated with surface segregation still remains intact in this case. This could be attributed to the improved tribological performance associated with the patterned morphology. Note that, such kind of mechanism is analogous to surface texturing on polymer surfaces [35]. In the case of surface texturing, friction behavior for boundary lubricated conditions show stable behavior. It is believed that, surface textures serve as micro-reservoirs for lubricating oil under sliding conditions. As a result, continuous supply of lubricating oil at the interface is possible, resulting in an improvement in the friction behavior. This observation is in accord with tribological experiments of ATSP/PTFE. In the case of dry condition, segregated components are sheared off and amalgamated on the surface. Some components are also transferred to the counter surface, which will be shown in the next section.

In the case of coatings, the upper surface is bounded by air or working environment while the lower surface is confined by the substrate or base material. Due to the presence of air or refrigerant/ lubricant, the upper surface undergoes different chemical and physical induced interactions, including chemisorption, diffusion, and adsorption. In addition to these chemical mechanisms, the physical state and nature of polymeric chains could also develop different properties for the top surface. Collectively, the properties, e.g., wettability, adhesion, friction and wear, of the top surface of a polymeric coatings differs significantly compared to bulk polymers due to these chemical and physical reasons. The morphology of the top surface usually changes due to these reasons, resulting in surface segregation and multiphase behavior. Note that, material enrichment on the surface associated with surface segregation could alter the tribological 
behavior. This is inherent nature of polymer materials with filler additives and surface segregation is related to the crosslinking process. Ming et al. showed that crosslinking procedures result in material enrichment, depending on the crosslinking agent [36].

Fig. 10 depicts the SEM surface morphology of PTFE/MoS ${ }_{2}$ coated disk sample. Fig 10(a,c) and $10(\mathrm{~b}, \mathrm{~d})$ represent the wear mode of this coating under dry and lubricated conditions, respectively. Surface cracks associated with micro-pitting were observed on the surface under lubricated conditions, compared to dry conditions. Under compressive loads and sliding, these pores can be filled with lubricant and result in an increased hydrostatic pressure beneath the surface. This would reduce the mechanical strength of the surface and will accelerate the material removal process. Furthermore, these surface cracks could act as the local sites of oil seepage into the coating materials. This would further enhance the wear process.

\section{2. $\quad$ Transfer layers}

In the case of contacting/sliding polymers, material transfer from the polymeric surface to the counter surface is a typical phenomenon $[37,38]$. Such kind of material transfer governs the overall tribological performance for polymeric-based interfaces. This is believed that, transfer films on the counter surface would act as a shielding for polymer surface against contact from hard metallic asperities. Note that, the transfer film can act as a third body lubricant for the interface, reducing the wear while maintaining low COF. However, it is not clear why transfer films are selectively developed and the mechanisms underpinning this transfer. It is widely accepted that material transfer occurs from the topmost surface of the polymer. Therefore, understanding the morphology and chemical composition of the topmost surface is critical to understand this material transfer process. The morphological integrity associated with better adhesion between the transfer film and the counter surface is also important to ensure a sustainable interface. 
In the case of ATSP/PTFE, material enrichment towards the air-polymer interface will come in contact with the counter surface first. Segmented particles will be sheared off and will transfer to the counter surface at a subsequent stage. Since ATSP has good adhesion with most metallic surfaces, the transferred ATSP particles would firmly attach to the 52100 steel counter-surfaces. Transfer of material can be hindered in the presence of liquid lubricant. Note that, a uniform transfer layer could result in a sustainable interface. On the other hand, the tribological performance can deteriorate if the migration of the polymers to the counter surface is restricted. The presence of lubricant is one kind of blockage for a successful polymer film transfer. In addition, the adhesion and chemical nature of the transfer films influence the friction and wear behavior. For example, PTFE has excellent transfer capability, resulting to a low friction coefficient due to PTFE versus PTFE sliding.

Fig. 11 shows the transfer film on the 52100 steel surface, where Fig. 11(a) represents the morphology of the transfer film under SEM mode, and Fig. 11(b) depicts the same topography under backscattered electron mode (BES). From the BES mode, it is evident that material transferred from ATSP/PTFE composite and attached on the steel counter-surface. Fig. 11(c) identifies intensities of chemical elements in the transfer film using Energy Dispersive Spectroscopy (note that the data is shown as the elements vary on a line scan). The spectra for three elements have been extracted namely, Fluorine, Oxygen and Carbon. Interestingly, fluorine has been identified almost in the entire scan length. This is due to the presence of $1234 \mathrm{yf}$ refrigerant that was present during the tribological experiments. Note that, refrigerant decomposes at the steel surface in the presence of r1234yf refrigerant [12-14]. However, with the migration of material from the polymer surface, the steel surface was covered with a transfer film. As a result, a drop in fluorine intensity is seen on the transfer film region. This would further support that the transfer film is consisted of ATSP material. Therefore, a transfer film of ATSP is more adhesive, facilitating ATSP versus ATSP sliding in the presence of r1234yf refrigerant. 
Also, since the NCT is about $180{ }^{\circ} \mathrm{C}$ in the case of ATSP/PTFE, it accelerates the ITR interactions on the surface. Therefore, micro-voids and micro-cracks would be self-healed, producing better morphological integrity, as also observed in the previous section.

Fig. 12 shows the transfer film developed on the 52100 steel surface slid against PTFE/MoS coating. EDS analysis identified the existence of fluorine on the transfer film. Thus, in the case of PTFE/MoS 2 , it is believed that PTFE particles transferred to the counter surface. Therefore, sliding occurred between PTFE/MoS 2 versus PTFE, producing a low COF trend. A line scan of chemical composition was also obtained to verify carbonaceous film transformation. From this line scan, it is believed that the transfer film consisted of PTFE (-C-F) materials, unlike the case of ATSP/PTFE.

Fig. 13 depicts BES images of 52100 steel surface tested under boundary lubrication. Specifically, Fig. 13(a) represents the morphology of 52100 steel surface slid against PTFE/MoS 2 , while Fig. 13(b) shows 52100 steel surface tested against PTFE/ATSP. In both cases, no transfer film is observed, neither continuous or patchy forms, unlike the dry condition case. This could be attributed to the presence of liquid (lubricant) film at the interface, limiting the ability to transfer material. In the case of PTFE/MoS 2 , the counter surface did not undergo any changes. This implied that, there was less interactions from lubricant and coating with the counter surface. As a result, continuous removal of the material occured due to the lack of transfer film on the counter surface. This also explains the antagonistic behavior between PTFE/MoS 2 -based polymeric coating and PAG lubricant in the presence of HFO-1234yf refrigerant. To the contrary, for PTFE/ATSP, ATSP particles attached to the counter surface as can been seen by the patchy transfers (circled black spots) in Fig. 13(b). A qualitative chemical composition analysis was carried out on the 52100 steel surface to verify this observation. EDS's spot analyzing tool was utilized to identify the chemical composition of the transferred particles to the counter surface. Interestingly, inside the black spots, the amount of carbon and oxygen 
increases significantly compared to outside. Additionnaly, no fluorine is obtained from this analysis. This implies transfer of segregated ATSP particles from the disk surface. Note that, ATSP consists of Carbon and Oxygen only. No chemical change was observed for the case of PTFE/MoS 2 as well as outside of the black spots in the casse of PTFE/ATSP. It is believed that the ATSP particles came off from segregated components. However, the low friction coefficient could be attributed to the presence of valleys on the surface. These micro-reservoirs could provide continuous replenishment of lubricant film during sliding operation. Therefore, PTFE/ATSP showed a synergestic effect with liquid lubricant system, which is very important, since its introduction in machinery will involve both lubricant and refrigerant.

\section{6. $\quad \mathrm{COF}$ and wear relation}

The tribological performance of different coatings was measured experimentally in the presence of r1234yf refrigerant and all the results are summarized in Fig. 14. ATSP/PTFE based coatings exhibited superior tribological performance under the specified testing conditions. A low friction coefficient along with low wear rate was found for these cases. These coatings also offered better performance under boundary lubrication conditions, Fig. 14(b).

When one considers the introduction of advanced polymeric coatings in machinery, such as airconditioning and refrigeration compressors, it is unlikely that the lubricant will be eliminated altogether, especially until confidence in such advanced coating systems is established. Moreover, in some cases the presence of liquid lubricant is necessary (e.g., for cooling). Therefore, it is obvious that polymeric coating and liquid lubricants will be present at the same time. For the case of PTFE/ATSP, a synergistic effect has been observed by reduction of COF by about $69 \%$. The wear behavior was also improved by $20 \%$ with the inclusion of PAG lubricant under boundary lubrication conditions. Material enrichment would provide the benefit of surface texturing, enhancing oil retention capabilities. PTFE/Pyrrolidone also exhibits synergistic effects 
in the presence of PAG/r1234yf environment. Improvement towards COF and wear resistance was $62 \%$ and $76 \%$, respectively. However, $\mathrm{PTFE} / \mathrm{MoS}_{2}$ shows a negative interaction with the PAG lubricant. Both COF and wear resistance dropped significantly in the presence of lubricant. This characteristic is attributed to the restriction of transfer film due to the presence of liquid lubricant at the interface. Interesting, fluorocarbon fails in both the dry and lubricated conditions. Therefore, no improvement towards the wear resistance was measured. However, dry fluorocarbon particles can act as third body lubricants, keeping the COF low. Conversely, lubricated fluorocarbon particles could lead to scuffing type failures of the interface as indicated by sharp increase in COF. In the case of PTFE/PEEK, the wear behavior was improved by $4.3 \%$, while the friction behavior was degraded by $9 \%$.

Comparative average wear rate and COF values (between unlubricated and boundary lubricated conditions) of the tested polymeric coatings is presented in Table 3. For better interpretation, the tabulated results are also depicted graphically in Fig 15. Clearly, PTFE/MoS 2 showed antagonistic performance compared to the other coatings in consideration. On the contrary, PTFE/ATSP and PTFE/Pyrrolidone exhibited superior performance compared to all tested coatings. However, PTFE/ATSP outperforms PTFE/Pyrrolidone under both boundary lubricated and unlubricated conditions from both wear and COF viewpoints. It is noted that, in the case of Fluorocarbon, the coating material was completely removed from the interface under both dry and lubricated conditions (and being a catastrophic event, we do not report wear rate). This change in wear behavior has been marked in Table 3 and Fig. 15 as "completely worn."

\section{Conclusions}

Polymeric coatings interact with the working refrigerant and could result in different tribological performance. Advanced ATSP/PTFE-based coatings outperform other state-of-the-art coatings under both dry and boundary lubricated conditions. A synergistic effect (69\% lower COF and 
$20 \%$ lower wear) is found for ATSP/PTFE coating and PAG lubricant. Conversely, PTFE/MoS 2 has showed adverse interactions with the lubricant, resulting in higher COF and higher wear. Surface segregation associated with material enrichment, via crosslinking process or coexistence of multiphase systems, offers tribo-beneficial effects. The valleys of segregated components can act as micro-reservoirs to enhance the oil retention capabilities under starved lubrication. As a result, continuous replenishment of lubricant supply is possible, which is the case for ATSP/PTFE. This phenomenon does not rely on the formation of transfer film on the counter surface. Note that, the presence of lubricant film at the interface delays or limits the ability of transfer materials from the polymer surface to the counter surface. Therefore, under starved lubrication conditions, the chemical nature and morphology of the topmost polymeric surface is critical as far as its tribological performance is concerned.

\section{Acknowledgments}

This research work was supported by 30 member companies of the Air-Conditioning and Refrigeration Center, an Industry University Cooperative Research Center at the University of Illinois at Urbana Champaign. Micromechanical and Chemical analysis were carried out at the Center for Microanalysis of Materials, University of Illinois at Urbana-Champaign, which is supported by the U.S. Department of Energy under Grant DEFG02-96-ER45439. The r1234yf refrigerant was provided by Honeywell International.

\section{References}

[1] Myshkin NK, Petrokovets MI, Kovalev AV. Tribology of polymers: Adhesion, friction, wear, and mass-transfer. Tribology International 2005; 38: 910-921.

[2] Czichos H, Klaffke D, Santer E, Woydt M. Advances in tribology: the materials point of view. Wear 1995; 190: 155-161. 
[3] Brostow W, Kovacevic V, Vrsaljko D, Whitworth J. Tribology of polymers and polymer based composites. Journal of Materials Education 2010; 32: 273-290.

[4] Nunez EE, Yeo SM, Polychronopolou K, Polycarpou AA. Tribological study of high bearing blended polymer-based coatings for air-conditioning and refrigeration compressors. Surface and Coatings Technology 2011; 205: 2994-3005.

[5] Dascalescu D, Polychronopolou K, Polycarpou AA. The significance of tribochemistry on the performance of PTFE-based coatings in $\mathrm{CO}_{2}$ refrigerant environment. Surface and Coatings Technology 2009; 204: 319-329.

[6] Yeo SM, Polycarpou AA. Tribological performance of PTFE- and PEEK-based coatings under oil-less compressor conditions. Wear 2012; 296: 638-647.

[7] Yeo SM, Polycarpou AA. Fretting experiments of advanced polymeric coatings and the effect of transfer films on their tribological behavior. Tribology International 2014; 79: 16-25.

[8] Biswas SK, Vijayan K. Friction and wear of PTFE - a review. Wear 1992; 158: 193-211.

[9] Tanaka K., Uchiyama Y., Toyooka S. The mechanism of wear of polytetrafluoroethylene. Wear 1973; 23: 153-172.

[10] Burris B, Sawyer WG, A low friction and ultra low wear rate PEEK/PTFE composite. Wear 2006; 261: 410-418.

[11] Lu ZP, Friedrich K. On sliding friction and wear of PEEK and its composites. Wear 1995; 181-183: 624-631.

[12] Spatz M, Minor B. HFO-1234yf low GWP refrigerant: a global sustainable solution for mobile air conditioning. SAE 2008 Alternate Refrigerant System Symposium, June 10-12, Scottsdale, Arizona.

[13] Zilio C, Brown JS, Schiochet G, Cavallini A. The refrigerant R1234yf in air conditioning systems, Energy 2011; 36: 6110-6120.

[14] Lee YL, Jung D. A brief performance comparison of R1234yf and R134a in a bench tester for automobile applications. Applied Thermal Engineering 2012; 35: 240-242.

[15] Akram MW, Polychronopoulou K, Polycarpou AA. Lubricity of environmentally friendly HFO-1234yf refrigerant. Tribology International 2013; 57: 92-100.

[16] Akram MW, Polychronopoulou K, Seeton C, Polycarpou AA. Tribological performance of environmentally friendly refrigerant HFO-1234yf under starved lubricated conditions. Wear 2013; 304: 191-201.

[17] Akram MW, Polychronopoulou K, Polycarpou AA. Tribological performance comparing different refrigerant-lubricant systems: The case of environmentally friendly HFO-1234yf refrigerant, Tribology International 2014; 78: 176-186. 
[18] Huang Y, Economy J. Wear properties of UHMWPE/aromatic thermosetting copolyester blends in unlubricated sliding. Wear 2007 ;262: 943-948.

[19] Demas NG, Zhang J, Polycarpou AA, Economy J. Tribological characterization of aromatic thermosetting Copolyester-PTFE blends in air conditioning compressor environment. Tribology Letters 2008; 29:253-258.

[20] Zhang J, Demas NG, Polycarpou AA, Economy J. A new family of low wears, low coefficient of friction polymer blends based on polytetrafluoroethylene and aromatic thermosetting polyester. Polymer Advanced Technologies 2008; 19: 1105-1112.

[21] Frich D, Goranov K, Schneggendurger L, Economy J. Novel high-temperature aromatic copolyester thermosets: synthesis, characterization, and physical properties. Macromolecules 1996; 29: 7734-7739.

[22] Frich D, Economy J. Thermally stable liquid crystalline thermosets based on aromatic copolyesters: Preparation and properties. Journal of Polymer Science Part A: Polymer Chemistry 1997; 35: 1061-1067.

[23] Reinitzer F. Beiträge zur Kenntniss des Cholesterins. Monatshefte für Chemie (Wien) 1988; 9: 421-441. [Translated]

[24] Cognard J. Lubrication with liquid crystals, Tribology and the Liquid-Crystalline State. ACS Symposium 1990; 441:1-48.

[25] Mori S, Iwata H. Relationship between tribological performance of liquid crystals and their molecular structure. Tribology International 1996; 29: 35-39.

[26] Frich D. The effect of interchain transesterification reactions on the development of aromatic copolyesters. Ph.D. Dissertation 1996; University of Illinois at Urbana-Champaign.

[27] Winer WO. Molybdenum disulfide as a lubricant: a review of the fundamental knowledge. Wear 1967; 10: 422-452.

[28] Chen JH, Gage PE. Tribological characteristics of $\mathrm{MoS}_{2}$ and PTFE filled polymeric bearings. Proc. 3rd Int. ASLE Conf. on Solid Lubrication 1984; Denver, CO: 320-327.

[29] Esteves ACC, Lyakhova K, Van der Ven LGL, Van Bentham RATM, De With G. Surface segregation of low surface energy polymeric dangling chains in a cross-linked polymer network investigated by a combined experimental-simulation approach. Macromolecules 2013; 46: 1993-2002.

[30] Tan H, Xie X, Li J, Zhong Y, Fu Q. Synthesis and surface mobility of segmented polyurethanes with fluorinated side chains attached to hard blocks. Polymer 2004; 45:14951502.

[31] Bukowski A, Rysz J, Scheffold F, Klein J, Bernasik A, Jedlinski J. Surface segregation in the minority component of the binary polymer mixture. Vacuum 1999; 54: 273-277. 
[32] Rysz J, Ermer H, Budkowski A, Lekka A, Bernasik A, Wrobel S, Brenn R, Lekki J, Jedlinski J. Depth profiling studies of the surface directed phase decomposition in thin polymer films. Vacuum 1999; 54: 303-307.

[33] Biver C, De Crevoisier G, Girault S, Mourran A, Pirri R, Leibler L. Microphase separation and wetting properties of palmitate-graft-poly(vinyl alcohol) films. Macromolecules 2002; 35: 2552-2559.

[34] Kun X. Design of aromatic thermosetting copolyester compositions and blends for thin film applications. Ph.D. Dissertation, University of Illinois at Urbana-Champaign (2002).

[35] He B, Chen W, Wang QJ. Surface texture effect on friction of a microtextured poly (dimethylsiloxane) (PDMS), Tribology Letter 2008; 31: 187-197.

[36] Ming W, Melis F, Van de Grampel RD, Van Ravenstein L, Tian M, Van der Linde R. Low surface energy films based on partially fluorinated isocyanates: the effects of curing temperature. Progress in Organic Coatings 2003; 48: 316-321.

[37] Bahadur S. The development of transfer layers and their role in polymer tribology. Wear 2000; 245: 92-99.

[38] Jintang G. Tribochemical effects in formation of polymer transfer film. Wear 2000; 245 : 100-106. 
Table 1: Experimental and operating conditions for polymer coatings

\begin{tabular}{lll}
\hline Parameters & Dry (Set 1) & Boundary (Set 2) \\
\hline Type & Unidirectiona & Unidirectional \\
Normal Load, N & 445 & 445 \\
Sliding Velocity, m/s & 3.6 & 3.6 \\
Chamber Pressure, $\mathrm{MPa}(\mathrm{r} 1234 \mathrm{yf})$ ) & 0.3 & 0.3 \\
Operating Temperature, ${ }^{\circ} \mathrm{C}$ & 90 & 90 \\
Liquid Lubricant & None (Dry) & PAG (300 SUS) \\
Duration, min & 30 & 30 \\
\hline
\end{tabular}


Table 2: Roughness and thickness of the polymeric coatings

\begin{tabular}{llll}
\hline Sample & Roughness $(\boldsymbol{\mu m})$ & Thickness $(\boldsymbol{\mu m})$ & Commercial Name \\
\hline PTFE/ATSP & $1.38 \pm 0.30$ & $20-25$ & ATSP \\
PTFE/Pyrrolidone & $1.25 \pm 0.20$ & $20-25$ & DuPont $^{\circledR}$ Teflon ${ }^{\circledR} 958-303$ \\
PTFE/MoS 2 & $1.14 \pm 0.25$ & $20-25$ & Fluorolon ${ }^{\circledR} 325$ \\
PTFE/PEEK & $1.47 \pm 0.36$ & $20-25$ & 1704 PEEK/PTFE \\
Fluorocarbon & $1.53 \pm 0.40$ & $30-35$ & Impreglon ${ }^{\circledR} 218$ \\
\hline
\end{tabular}


Table 3: Comparative wear performance of polymeric coatings (set 1 and set 2)

\begin{tabular}{|c|c|c|c|}
\hline Coating & $\begin{array}{l}\text { Average Wear Rate, } \\
\text { mm }^{3} / \mathrm{N}-\mathrm{m} \\
\text { (Unlubricated) }\end{array}$ & $\begin{array}{l}\text { Average Wear Rate, } \\
\text { mm }^{3} / \mathbf{N}-\mathbf{m} \\
\text { (Boundary Lubricated) }\end{array}$ & \% of Change \\
\hline PTFE/ATSP & $8.50 \times 10^{-7}$ & $6.80 \times 10^{-7}$ & 20.00 \\
\hline PTFE/PEEK & $5.10 \times 10^{-6}$ & $4.90 \times 10^{-6}$ & 3.900 \\
\hline $\mathrm{PTFE} / \mathrm{MoS}_{2}$ & $3.00 \times 10^{-6}$ & $1.49 \times 10^{-5}$ & -396.7 \\
\hline PTFE/ Pyrrolidone & $7.80 \times 10^{-6}$ & $1.80 \times 10^{-6}$ & 76.90 \\
\hline Fluorocarbon & Completely Worn & Completely worn & -- \\
\hline
\end{tabular}


Fig. 1. Oligomers: C2 and A1 for ATSP based polymeric coatings.

Fig. 2. (a) Experimental simulation of swash plate compressor using pin-on-disk configuration, (b) 52100 steel shoe with crowned shape, and (c) cross section of polymeric coating.

Fig. 3. Frictional behavior of different polymeric coatings under HFO-1234yf refrigerant: (a) no liquid lubricant (dry) conditions, and (b) boundary lubricated conditions (PAG lubricant).

Fig. 4. Optical microscopic images of five different polymeric coatings (tested under dry conditions): (a) PTFE/ATSP, (b) PTFE/Pyrrolidone, (c) Fluorocarbon, (d) PTFE/PEEK, (e) $\mathrm{PTFE} / \mathrm{MoS}_{2}$ [Arrows show the direction of sliding].

Fig. 5. Optical microscopic images of five different polymeric coatings (tested under boundary lubricated conditions): (a) PTFE/ATSP, (b) PTFE/Pyrrolidone, (c) Fluorocarbon, (d) PTFE/PEEK, (e) PTFE/MoS 2 [Arrows show the direction of sliding].

Fig. 6. Wear profiles of the polymeric coatings tested under both dry and boundary lubricated conditions: (a) PTFE/ATSP, (b) PTFE/Pyrrolidone, (c) Fluorocarbon, (d) PTFE/PEEK, (e) $\mathrm{PTFE} / \mathrm{MoS}_{2}$.

Fig. 7. Durability tribological results (12000 m sliding distance): (a) COF under dry conditions, (b) COF under boundary lubricated conditions, (c) near contact temperature (NCT) under dry conditions, and (d) NCT under boundary lubricated conditions.

Fig 8. Wear profilometric analysis: (a) under unlubricated condition, (b) under boundary lubricated condition (durability experiments, $12000 \mathrm{~m}$ sliding distance).

Fig. 9. SEM morphology of ATSP/PTFE: (a) untested sample, (b) worn sample after triboexperiment under lubricated condition, (c) worn sample after dry condition.

Fig. 10. SEM morphology micrographs of PTFE/MoS 2 based polymeric coating after tribological testing: (a) (c) dry condition, (b) (d) lubricated condition.

Fig. 11. Transfer layer on the counter 52100 steel shoe (a) SEM micrograph, (b) Backscattered electron micrograph, (c) line scan of EDS analysis [red arrow in (a) indicates direction of scan].

Fig. 12. (a) Morphology and (b), (c) chemical composition of 52100 steel surface slid against $\mathrm{PTFE} / \mathrm{MoS}_{2}$.

Fig. 13. Backscattered electron micrograph of the 52100 steel slid against (a) PTFE/MoS 2 and (b) PTFE/ATSP under boundary lubricated conditions.

Fig 14. Summary of the tribological performance of five different polymer coating systems (a) unlubricated, (b) boundary lubricated conditions. 
Fig. 15. Percent change in tribological performance of polymeric coatings, comparing unlubricated and PAG boundary lubrication conditions. 


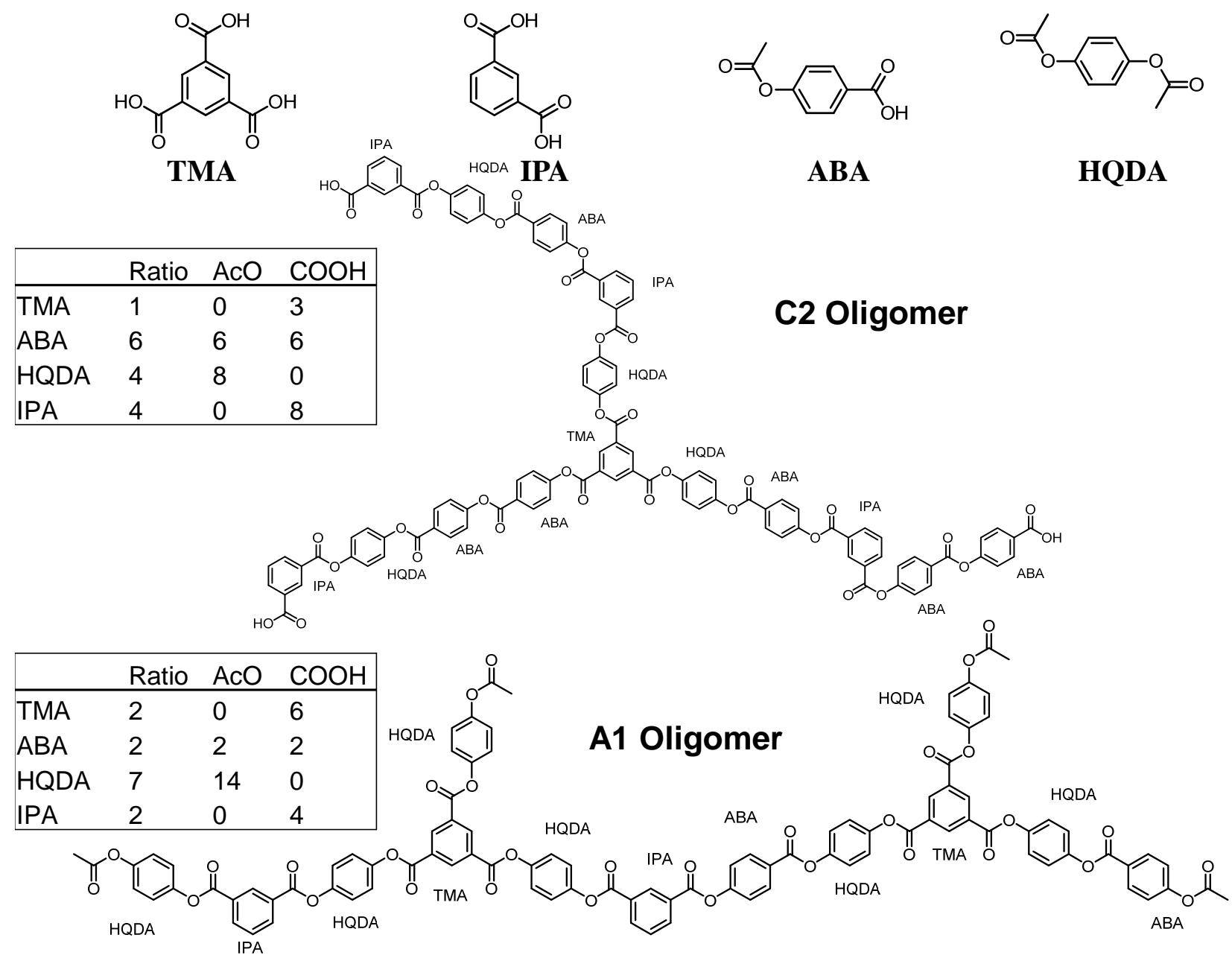

Fig. 1

29 
a)

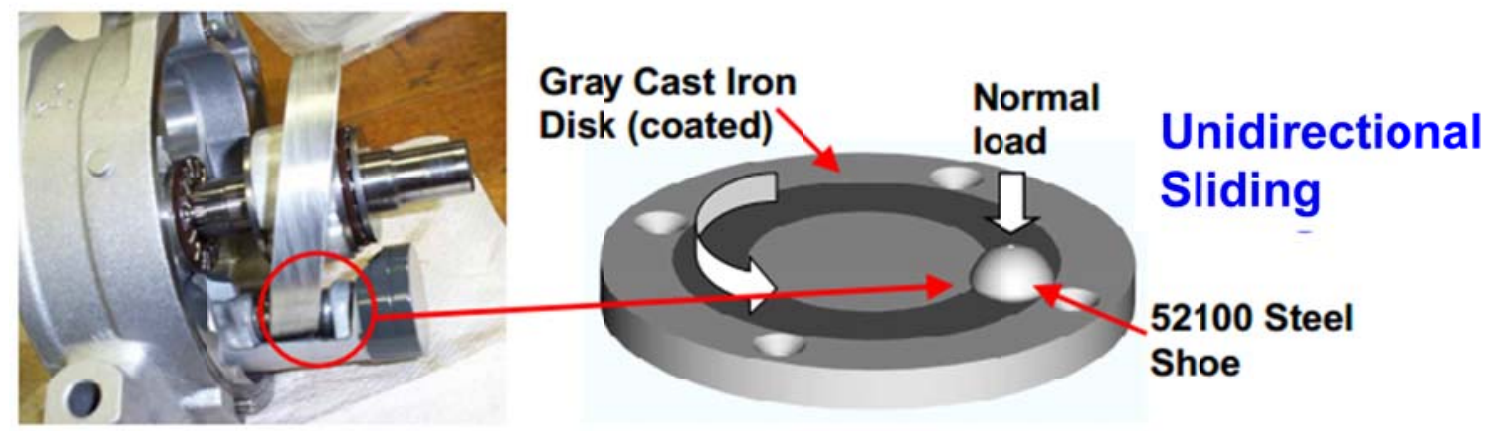

b)
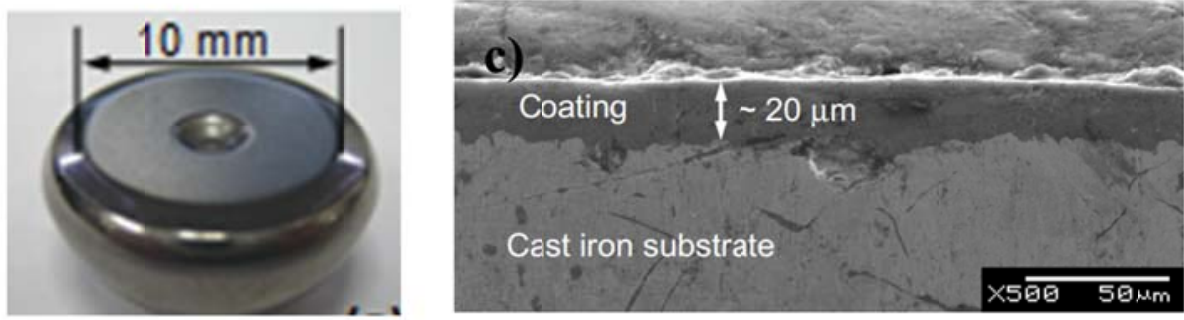

Fig. 2 

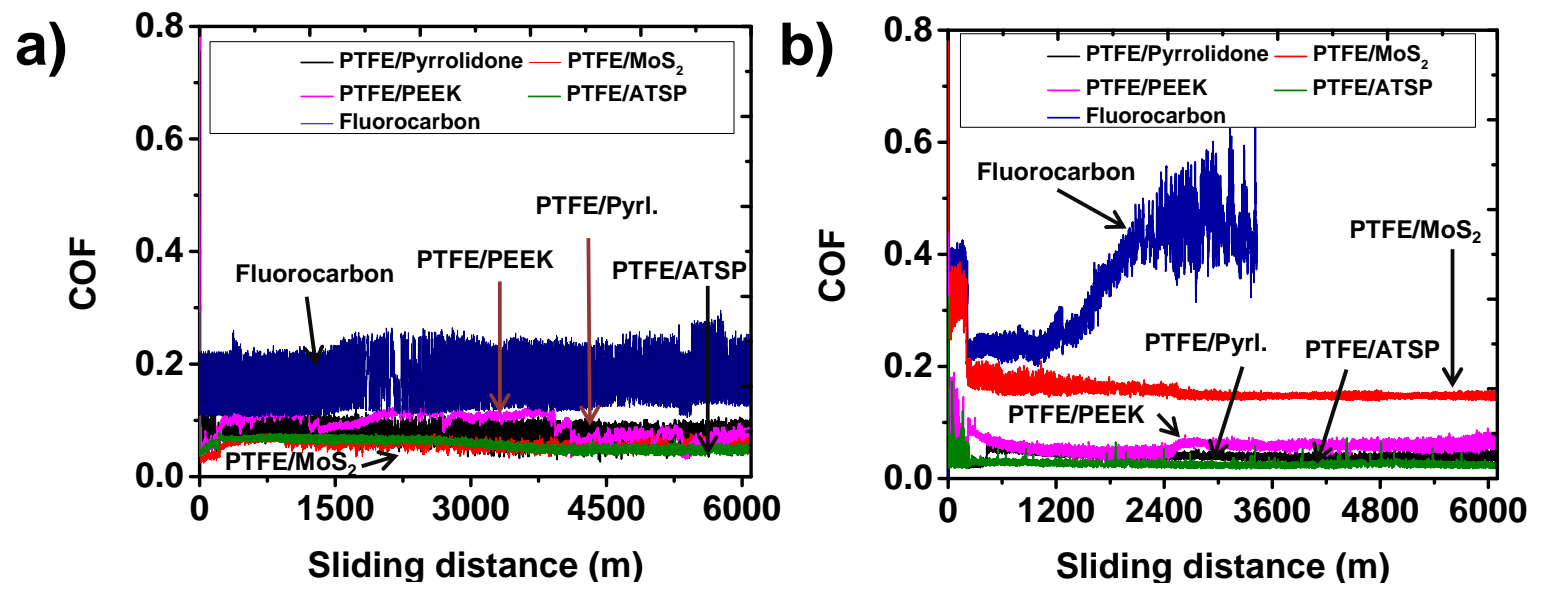

Fig. 3 

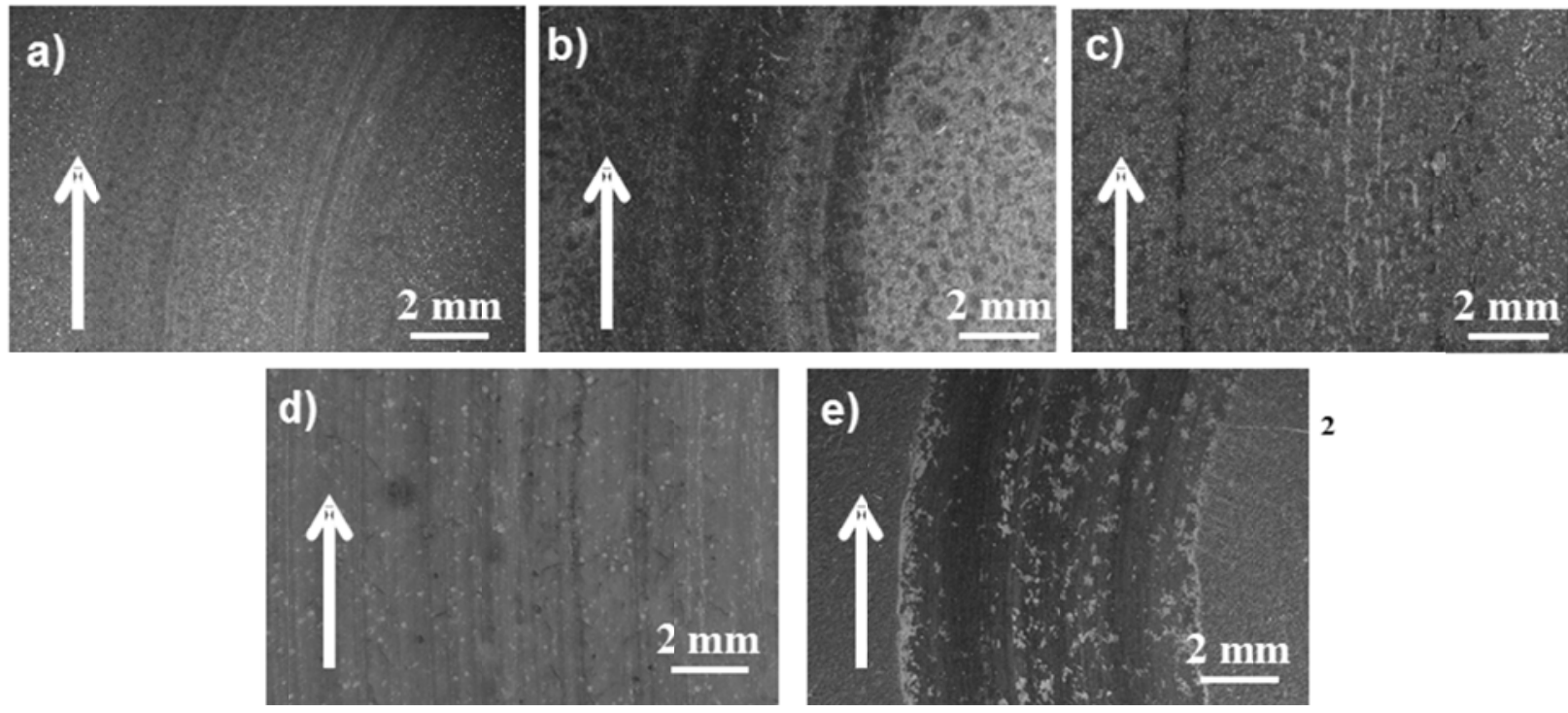

Fig. 4 

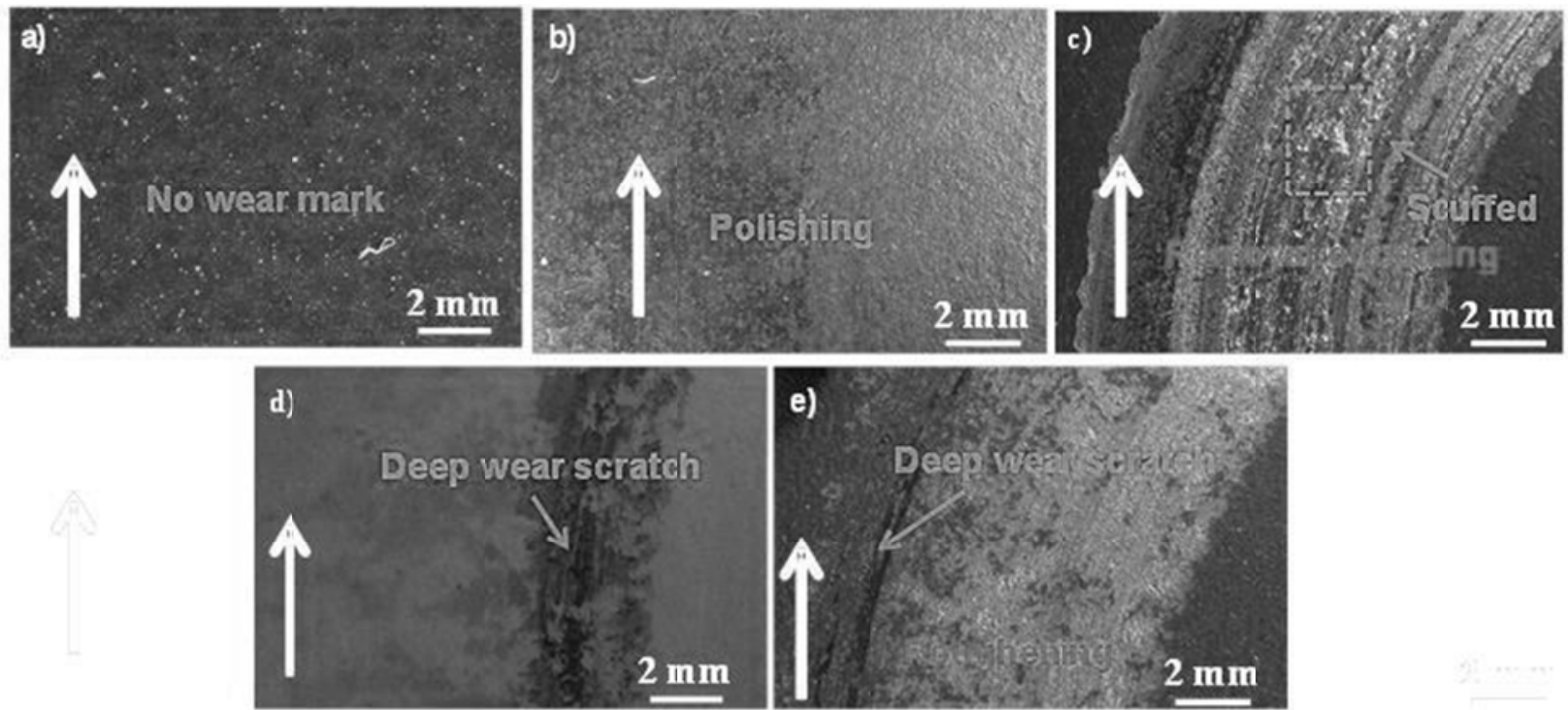

Fig. 5 

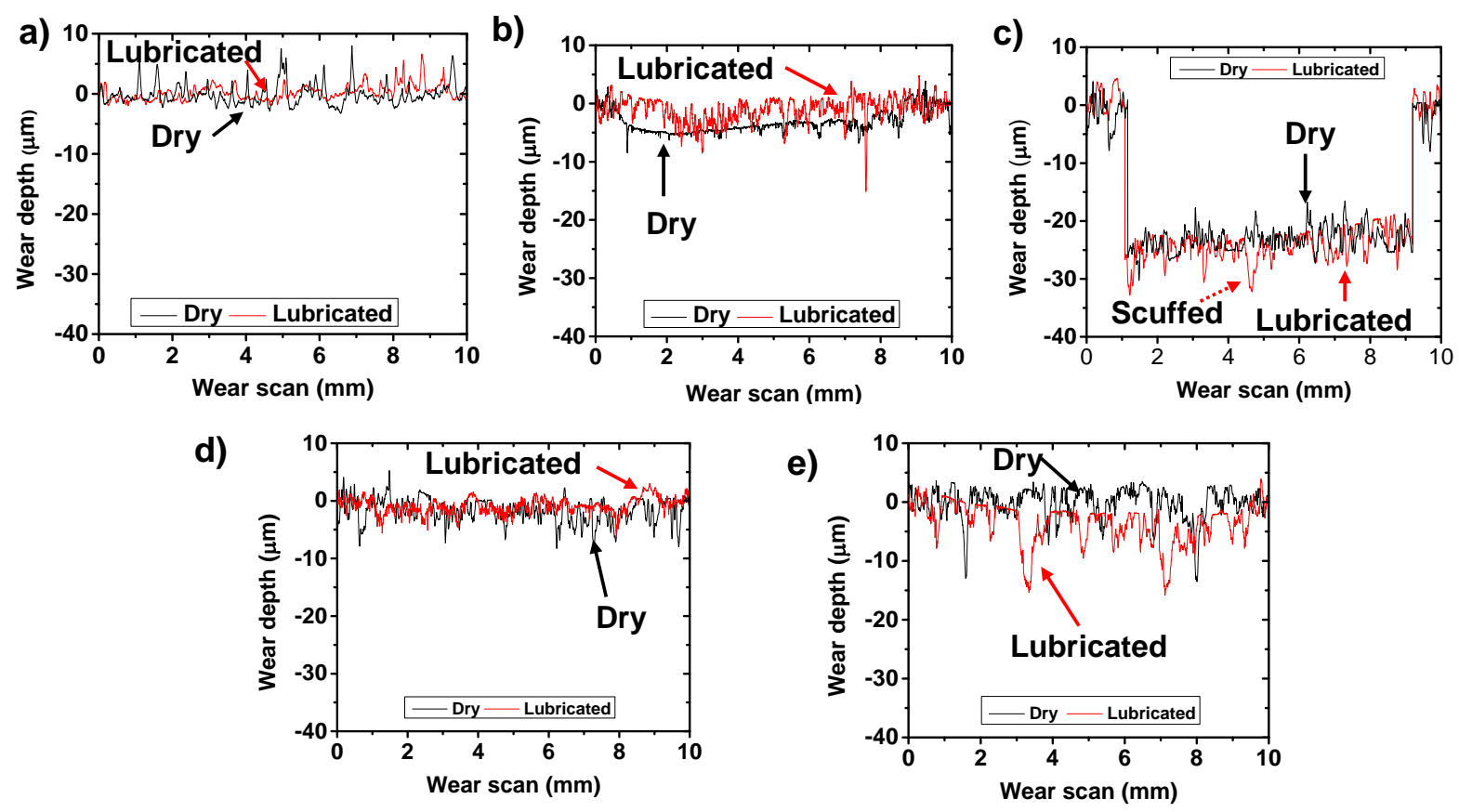

Fig. 6 

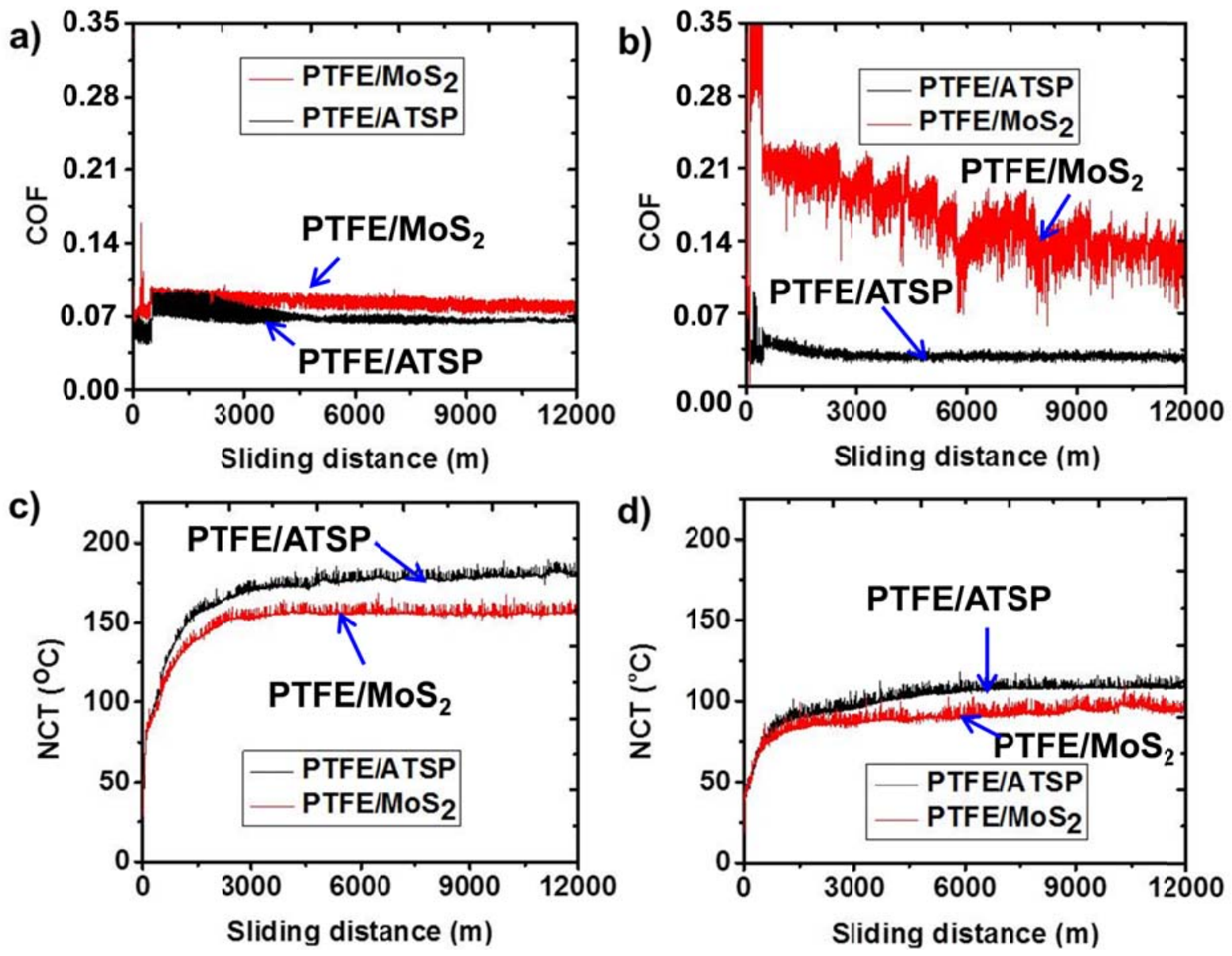

Fig. 7 

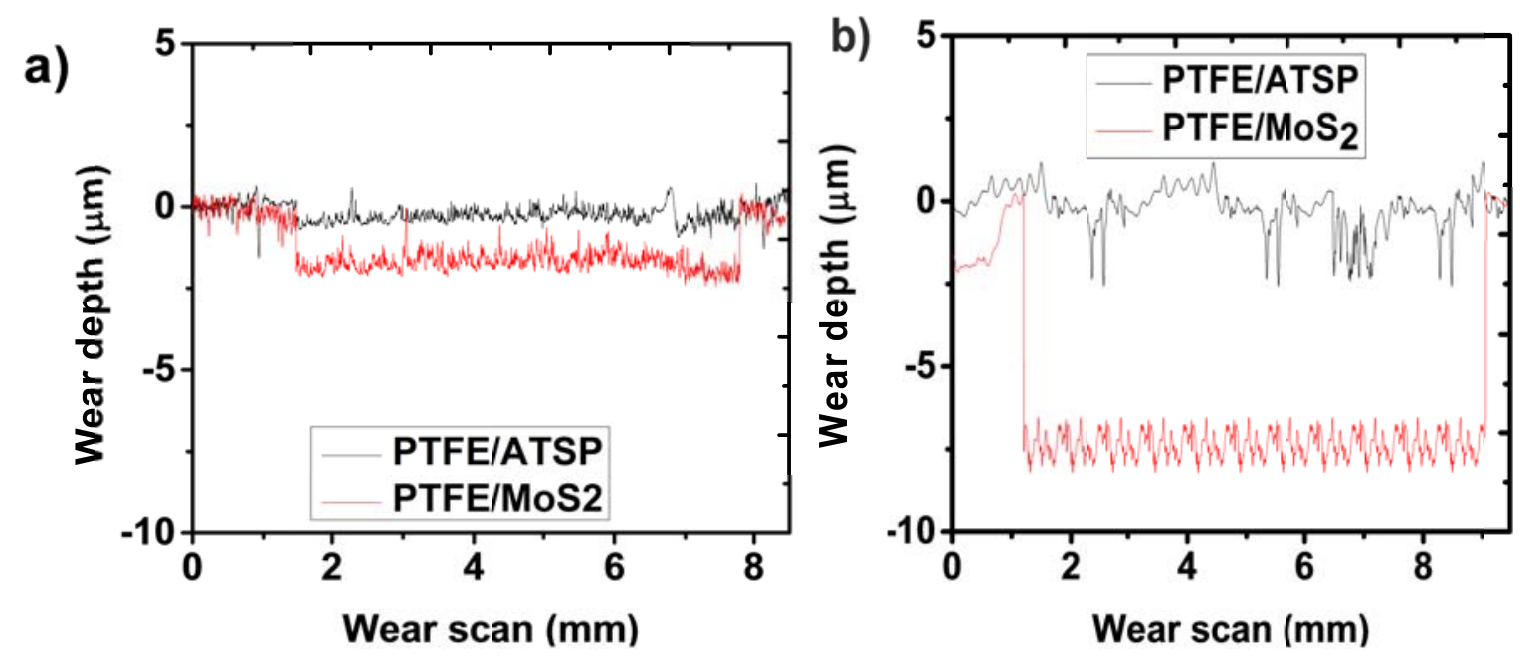

Fig. 8 

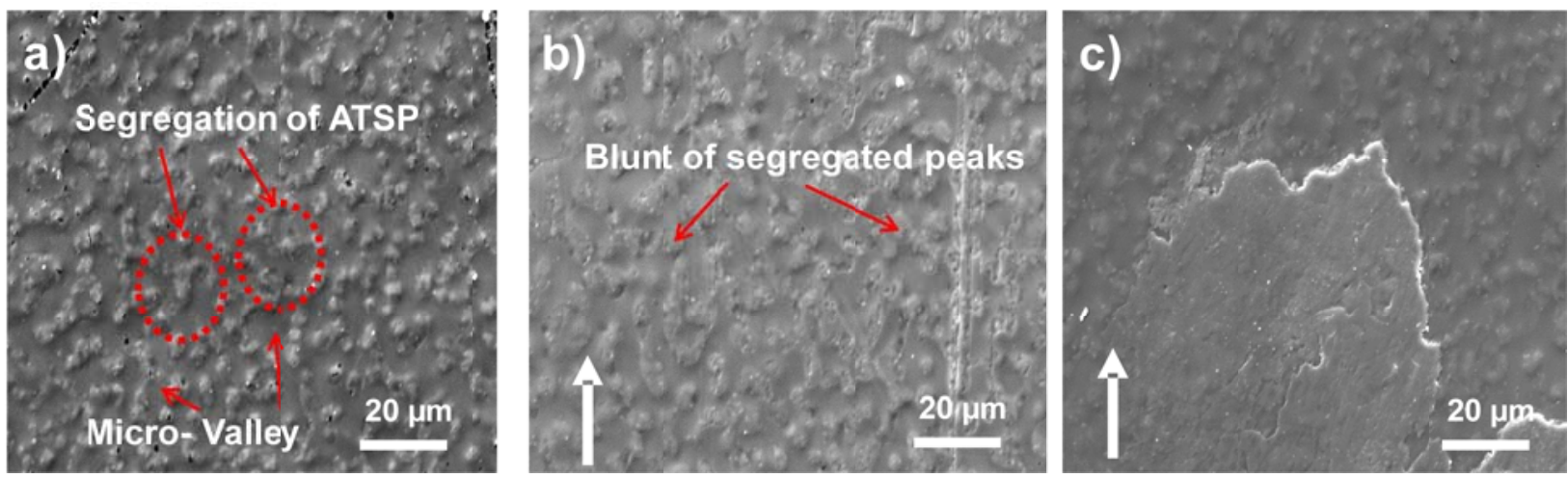

Fig. 9 

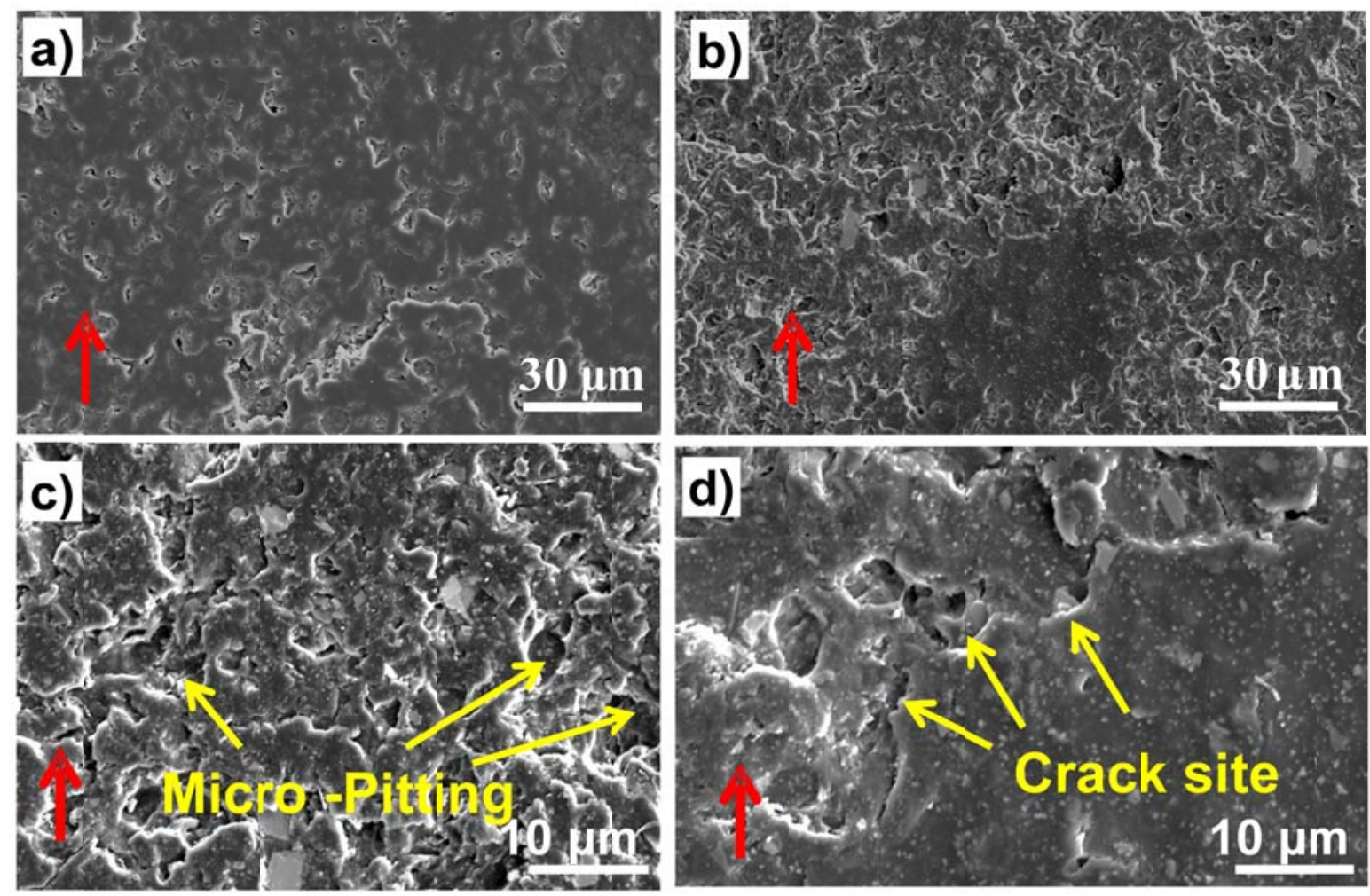

Fig. 10 

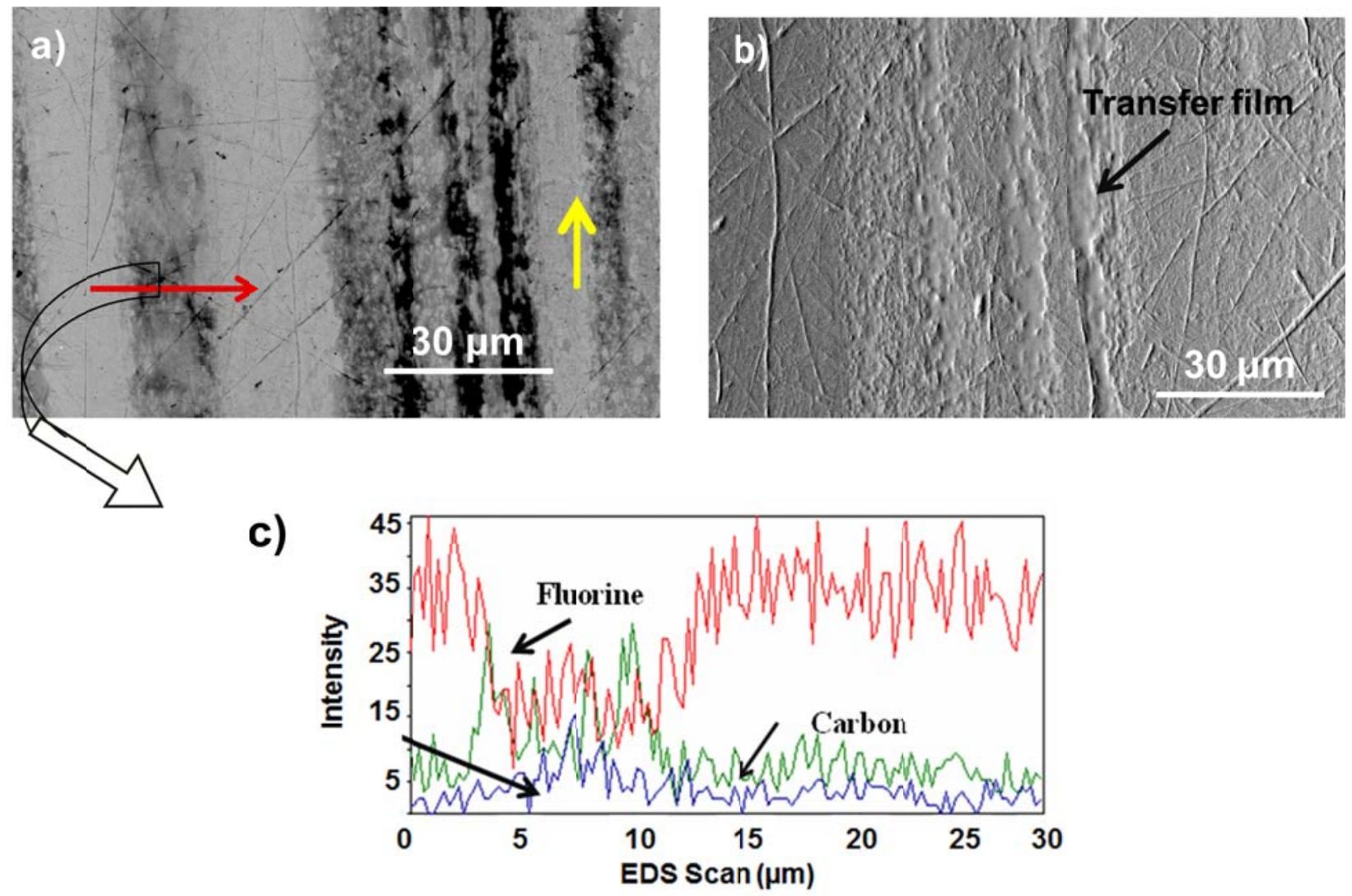

Fig. 11 


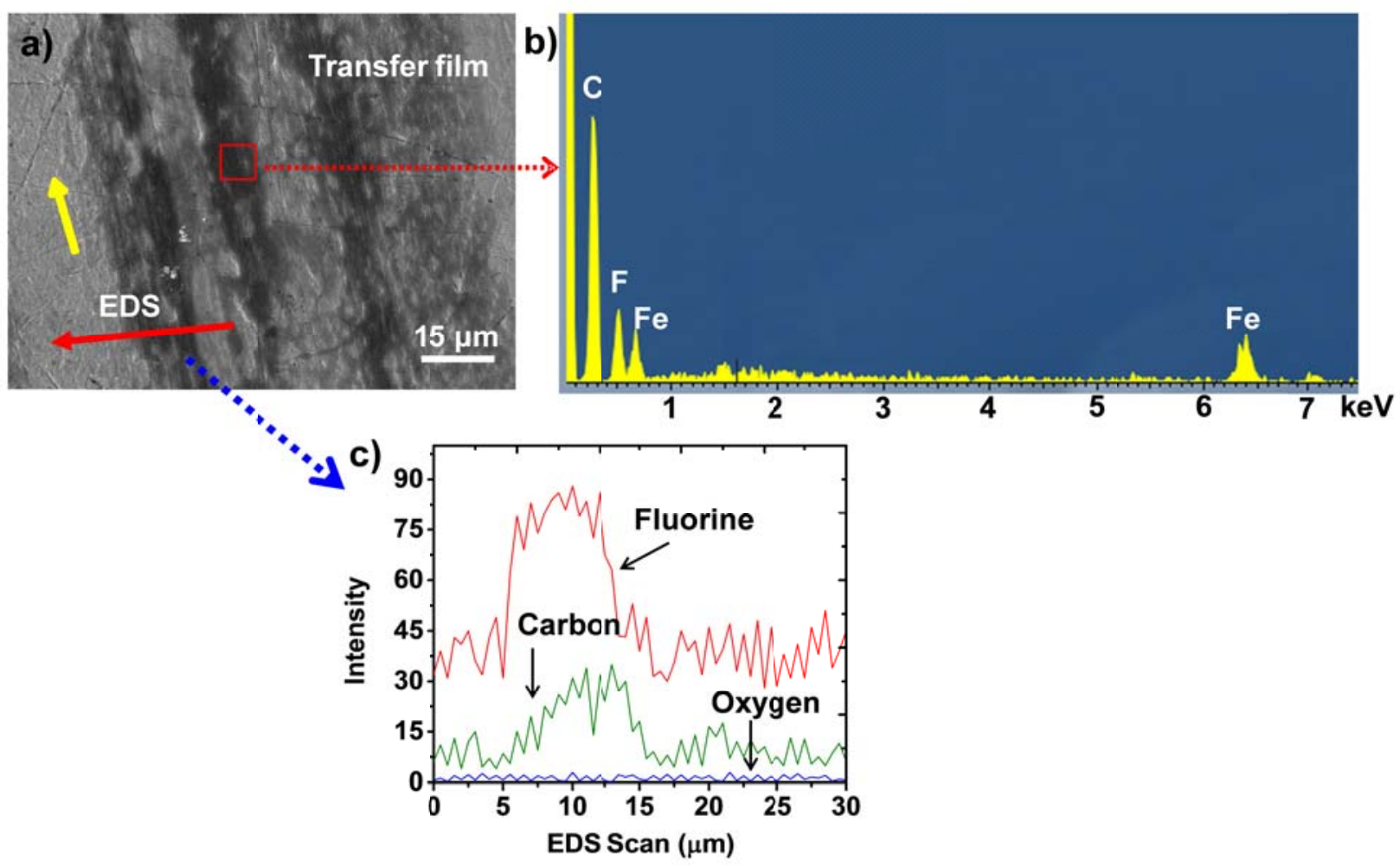

Fig. 12 

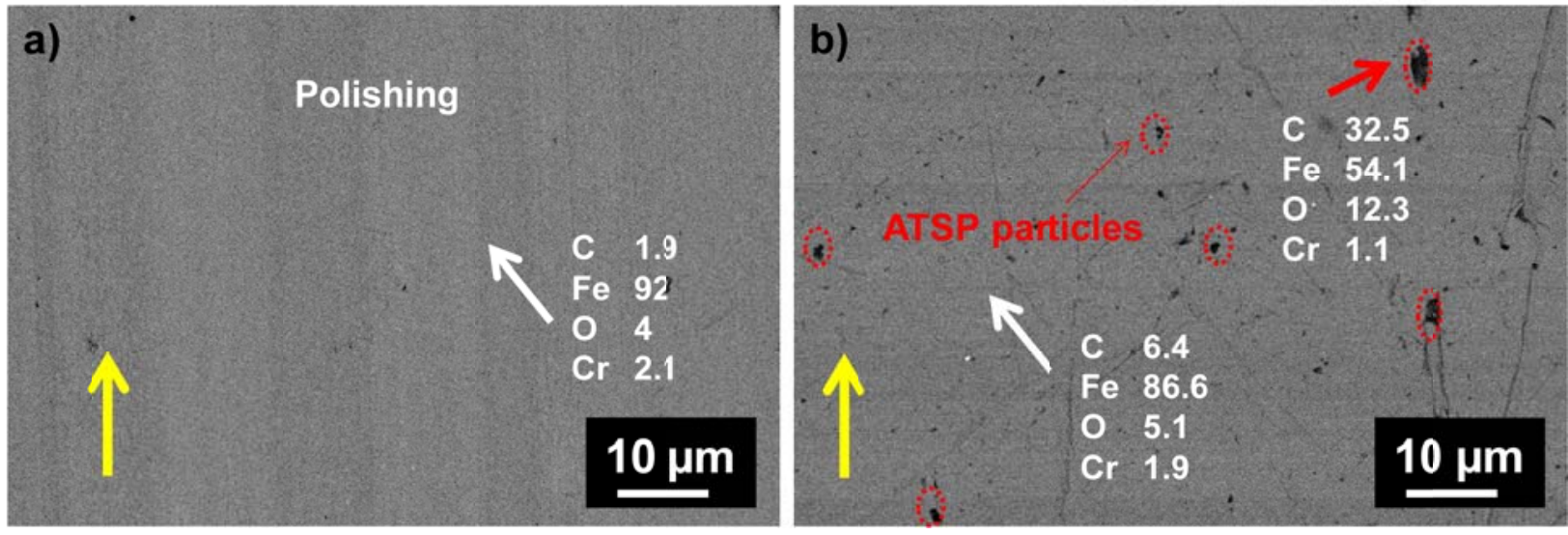

Fig. 13 

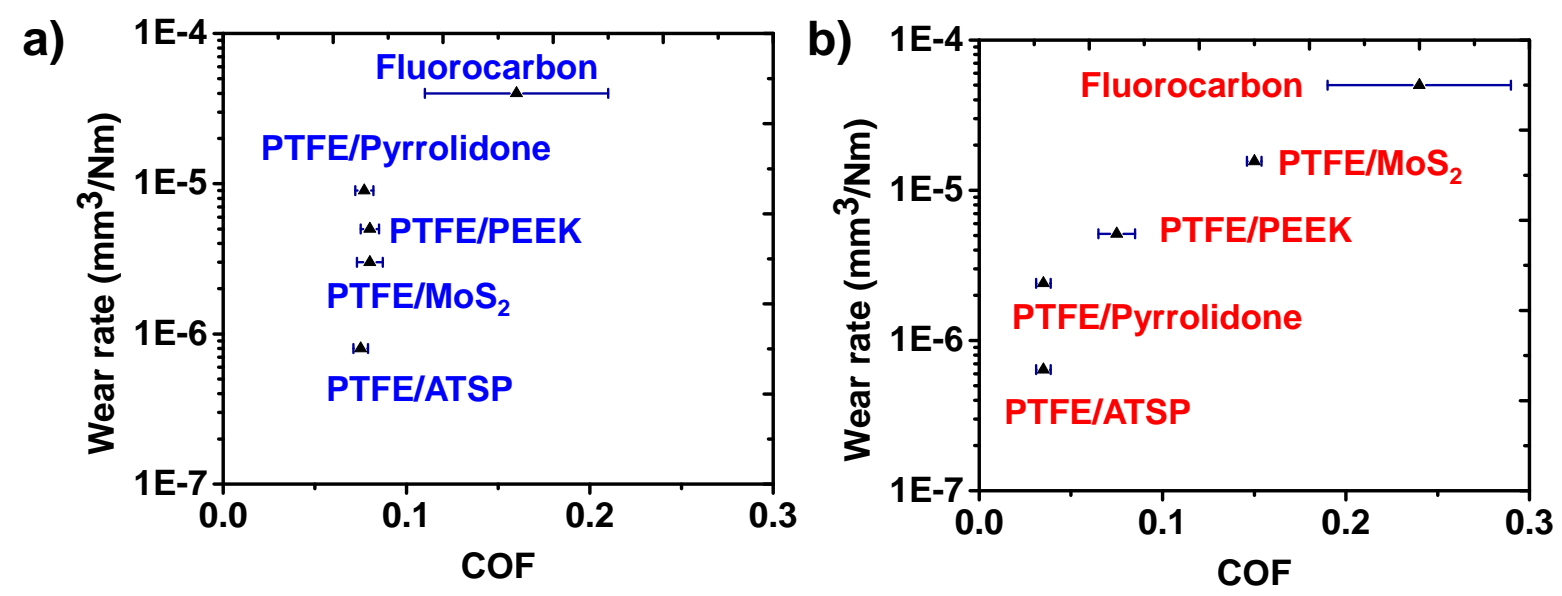

Fig. 14 


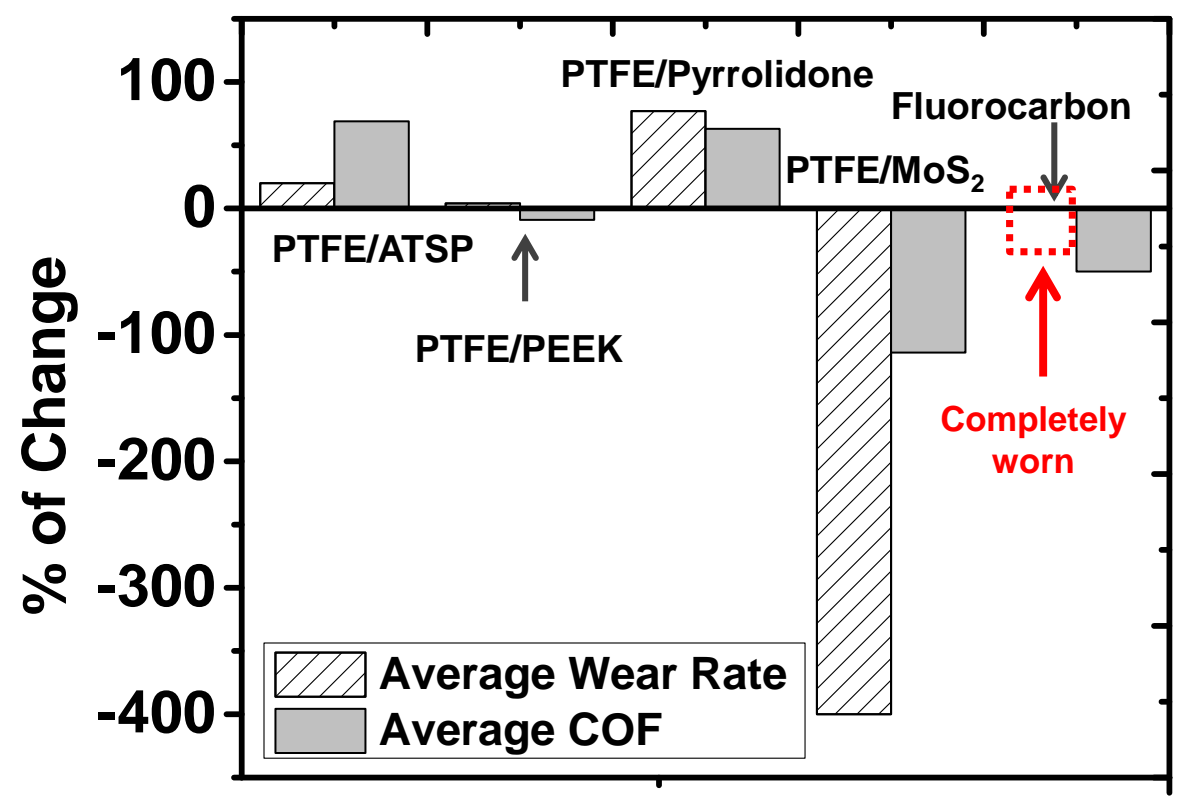

Fig. 15 